\title{
Rich water flow, live water revitalizes the countryside-—Rural water resources utilization design under the rural revitalization \\ strategy
}

\author{
DeXiang Deng, KaiGe Liu and Xi Zhou* \\ Chongqing University of Posts and Telecommunications
}

\begin{abstract}
Revitalizing the countryside should first develop water resources. The rational use of rural water resources will greatly enhance the endogenous power of rural revitalization, help to achieve the ${ }^{1}$ strategic rural revitalization goal of rich water and longevity, and promote the sustainable revitalization of rural areas in China.
\end{abstract}

Water is a spiritual symbol of the Chinese clan, and the Chinese clan is also the most adept at designing and utilizing water resources. In the ancient agricultural society of China, the design and utilization of each water resource led to the civilization of the dynasty and the country's prosperity, and represent the elevation of culture. Dujiangyan's design and its wise utilization of water created the "rich land - Chengdu", which was listed on the 2000 World Cultural Heritage List by UNESCO. The design of the Lingqu became a strategic design that contributed greatly for unifying and developing Lingnan after the Qin Dynasty unified the six countries. It was hailed as the "Pearl of Ancient World Water Conservancy Architecture", and listed on the World Irrigation Project Heritage List on August 13, 2018, during the 69th International Committee of the International Commission on Irrigation and Drainage. The Grand Canal is the highest achievement in the design and utilization of water resources in ancient China. It is the cornerstone of China to be one of the four ancient civilizations. It was approved for inclusion in the World Heritage List at the 38th World Heritage Conference on June 22, 2014.

After the establishment of the People's Republic of China, more attention has been paid to the design, development and utilization of water resources. In the 1950s and 1960s, the popularization of rural water conservancy design and utilization entered a climax, designing and developing reservoirs, ponds and irrigation channel water conservancy engineering systems benefited almost all villages; "Artificial Tianhe" - Hongqi Canal, Xiaolangdi Water Conservancy Project, Sanmenxia Water Conservancy Project, Three Gorges Dam, Gezhouba Water Conservancy Project, South-to-North Water Transfer Project, and water supply projects such as the water supply project in Tianjin, are major designs and use of important water resources and socialist undertakings under the leadership of the Communist Party.

When China entered a new era of socialism, rural revitalization became an important national development strategy. China's rural revival requires the drive of both endogenous and exogenous forces. Endogenous power is mainly the accumulation, utilization and ecological protection of rural resources. Exogenous forces are this generation's productivity, science and technology, capital investment and policy-driven production. The rural revival horn has already sounded, and the exogenous forces are strong. How to improve the endogenous power and exogenous forces of rural revitalization and jointly promote the sustainable revitalization of rural areas has become an important topic and theme. In terms of endogenous power, water resource is one of the most essential rural resource and the root of the

*Corresponding author:342862686@qq.com 
ecological environment. Therefore, rational design, development and utilization of rural water resources will greatly enhance the endogenous power of rural revitalization, and ensure rich water resources and long-term mobile water resources, as well as achieving the rural revitalization strategic goals.

\section{The overall planning and design of rural water resources, classification design and utilization.}

The water resource utilization rate is extremely low in the countryside, especially the loss of rainwater resources is resulting in severe water shortage in many rural dry seasons. For some "water-scarce" villages, the total amount of water resources is actually sufficient to supply the villagers' production and domestic water demand. However, due to the lack of overall planning and proper utilization of water resources, the rain season usually ends with over-slopes, water and soil losses, and flood disasters, making the villagers' production and life difficult. Then, in the dry season, the land turns cracked, the dust is rising, and the people's livelihood tend to be troublesome. Most of the backward villages, especially in the northwest, its situations are mainly caused by the lack of rational distribution of rainwater resources. Some villages lack the planning and utilization of rainwater resources, excessively exploit groundwater for agricultural irrigation and drinking water for humans and livestocks, deteriorate the groundwater ecology, which not only cause the groundwater resources to shrink, but also extends to the surface subsidence and subsidence of secondary disasters.

Therefore, to revitalize the villages, we must firstly plan and design based on the total amount of local water resources, rationally allocate and distribute rainwater resources and groundwater resources, and ensure that the villages have daily water for production and to support basic life to build the first layer of foundation. On the basis of scientific planning of water resources, adopting classified water use based on local conditions, to satisfy water supply for ecological conservation, drinking water for humans and livestocks, wild animals and birds, water for agricultural irrigation, processing water for agricultural and sideline products, water for rural industrial use, and to achieve water supply targets.

\section{Promote rural water storage design, rich in water and rich in the people.}

The low utilization rate of water resources has become an important obstacle to rural development. China's rural areas are vast, sparsely populated, scattered residents, which made centralized water supply, like urban for villagers' lives and agricultural production, difficult to achieve in a short period of time. Only the scientific water storage design according to local conditions could improve the water storage capacity of the village, and making the rural water resources prosperous is the road to sustainable use of rural water resources, and it is the only way for rural revitalization

\subsection{Rural rainwater storage design.}

Rainwater is the most important part of rural water resources. The effective reservoir design of rural rainwater resources can not only alleviate floods, but also serve as water supply for rainy seasons. It can also reduce excessive consumption of groundwater resources in rural areas, preventing the destruction of environmental ecology. Designing and constructing a good rural rainwater storage system has become an urgent task for rural revitalization.

\subsubsection{Designing rainwater storage forms and storage facilities based on rural topography.}

China has complex terrain and diverse landforms. One or several types of rainwater storage models cannot meet the water storage needs of the vast rural areas of China. Professional water conservancy designers should cooperate with agricultural and forestry experts, ecological environment experts, and art designers, to scientifically design the rainwater storage forms and storage facilities based on local conditions such as the environmental topography, agriculture, 
forestry production, and ecological conservation needs. It is forbidden to use so-called reproducible water storage forms, experiences, and programs that are popular everywhere.

\subsubsection{Rainwater grading reservoir design based on terrain height difference.}

The height difference of the terrain not only provides conditions for rainwater loss, but also provides a convenient condition for the grading reservoir of rainwater. The grading water storage design collects the rainwater resources as much as possible through the rainwater layer, for the occasional needs and for the deployment of different seasons. Of course, the grading water storage design is not a simple design involving construction of layers of water storage facilities, including forest water storage, surface water storage, geological water storage, mountain pond water storage, facility water storage, intercept water storage, wetland water storage, etc. It is a scientific and rational combination design of multi-form water storage.

\subsection{3 vigorously promote the design of field water storage.}

Field water storage is an ecological rainwater harvesting method with good water storage capacity and low economic input. Water storage in the field can preserve water, protect soil, maintain fertility, enhance drought resistance, and purify rainwater through soil absorption and penetration, replenish groundwater, and regulate water cycle. Water storage in mountain cascades prevents heavy rains from easing the erosion of surface runoff and slows down soil erosion; water storage in plain areas allows rainwater to be infiltrated and infiltrated to improve rainwater utilization. At present, for a variety of reasons, the rural land is abandoned, and the water storage capacity of the rural soil is not strong. The design of the water storage capacity of the soil should be vigorously promoted to effectively store the rainwater.

\subsubsection{Design and promotion of house rainwater storage.}

Rural household and institutional water use is one of the main ways of rural water consumption, and it is more about the consumption of groundwater resources in the form of spring water use. In order to reduce the consumption of groundwater resources, rainwater collection and storage schemes are designed according to the characteristics of houses in different regions, and promoted in the region. Such design will help achieving self-storage of rainwater for each household and unit, satisfying family life drinking, pulp washing, watering and each, meet the households' needs to use water for production and life, reduce the load of rural groundwater resources, and vigorously improve the utilization rate of rainwater resources.

\section{2 storage design of spring water.}

The spring water is mainly groundwater, which is the water resource that is traditionally used in rural areas. In the mountainous villages, the natural springs of the mountains are used. The plains mostly use underground wells to mine groundwater. Carrying out the reservoir design of spring water will effectively prevent the excessive loss of spring water, and build a situation of coordinated development and utilization of spring water resources and rain water resources.

\subsection{Redesign and utilization of traditional water storage facilities.}

China's agricultural civilization has a wealth of water storage facilities, mainly artificial lakes, reservoirs, mountain ponds, artificial wells, etc., some have been abandoned, some years of disrepair have potential safety hazards, or leakage, water storage capacity is reduced. The village should be used as a unit to conduct comprehensive statistics on the heritage resources of traditional water storage facilities, and comprehensively explore the hidden dangers of safety, and then carry out redesign and construction to use water storage. 


\section{Living water design keeps the vitality of rural water resources.}

The rural water storage design is to ensure that water resources are not lost or lost as much as possible, to provide basic guarantee for the full use of water resources, to carry out rural living water design, to make the reservoir water resources flexibly deploy and effectively use, to achieve the living and revitalizing. The goal is to design synergies with rural water storage design.

\subsection{Design a trench network connecting the various water storage facilities.}

The design of the ditch network should be clear and order, the network opening and closing, the connection can be controlled, the water volume can be adjusted to ensure accurate water use, effective control, so that the stored water resources can be alive and maximize the effective use; the overall design of the new and old ditch canal In order to reduce investment and increase efficiency. Classified design facilities make water vibrant

\subsection{Classification design facilities to make water vibrant.}

The live water path is designed to meet the needs of the rural water supply. For example, ecological conservation design surface runoff and surface infiltration for water supply, human and animal drinking water design pipeline sealed water supply, agricultural irrigation design ditch and water supply. In the highland and low-lying water resources imbalance, the design of high-pressure water supply for pipelines should be designed to transport low-lying and abundant water resources to high-altitude water storage facilities, and then irrigate and infiltrate into low-lying areas for storage to form a water cycle.

\subsection{Sewage activation design.}

Sewage discharged from rural villagers' domestic wastewater, human and animal waste, small factories, small workshops, etc., has become an important source of pollution for rural environmental pollution, and has caused serious damage to groundwater ecology. The policy-driven rural sewage activation design is treated by biochemical degradation and special equipment technology to become an active water source that meets the reuse or environmental emission standards for reuse.

\section{Scientific and systematic nature of rural water use design.}

The revitalization and sustainable development of the countryside is inseparable from the objective practical activities of the natural world. This requires us to rationally design and utilize rural water resources on the basis of respecting the objective laws of nature.

\subsection{Respect the objective laws of water environment and maintain the activity of rural water resources.}

Driven by the rural revitalization strategy, the continuous construction of rural road traffic, electricity, water conservancy and other infrastructure construction and production houses, tourism projects, and other projects all directly or indirectly affect or change the original law of movement of rural water resources. Therefore, rural revitalization should respect the objective laws of the water environment and the carrying capacity of the water resources environment, and rationally carry out the design of water resources and the construction of appropriate rural revitalization projects.

Runoff, evaporation and precipitation are the objective movement rules of water cycle and the three most important links in the water cycle. The water cycle formed by these three links determines the total amount of 
water resources in an area. In the design of rural water resources utilization and rural revitalization projects, the law of water cycle should be respected to ensure the activity of water resources.

\subsection{The design of rural water resources should be based on the premise of protecting water ecology.}

The water ecological environment relies on the self-purification of water body. "the concentration of pollutants in wastewater can be reduced by physical, chemical and biological effects, and the wastewater can be decomposed by microorganisms, thus returning the water from impurity to cleanliness." [1] after a period of time, the water usually returns to its pre-polluted state. In underdeveloped villages, depending on the self-purification capacity of water bodies, the ecological environment of water resources is better. However, the revitalization of rural areas will inevitably increase the carrying capacity of the water environment and ecology. The limited self-purification capacity of water bodies cannot bear the overloaded pollution sources, so we must design relevant schemes to purify the overloaded pollution sources. In addition, the development of rural revitalization should be limited by the carrying load of water resources, so as to develop projects that consume less water resources, have zero or less environmental pollution, and carry out the design and reuse of water resources on the premise of protecting water ecology.

\subsection{Systematic design of rural water resource utilization.}

The design and utilization of rural water resources should not be loose, isolated, and spontaneous. It should be a systematic use design at the government level; it should be carefully designed based on the total amount of water resources in the region, combining regional geology, topography, landforms and other resource advantages, with considerations on local business characteristics, and regional production and lifestyle.

\section{Conclusion.}

Water is the lifeline of rural areas, and also the first cornerstone of rural revitalization. Rational design and utilization of rural water resources will help us to build a rich and long flow of rural water and to achieve the long-lasting revitalization of rural .

\section{References:}

1. Mingdao. Geography common sense quick-checking and quick-use large complete set [D]. China Legal Publishing House (2014)

2. A.H. Liu, H. Wang, Y.F. Chen, H.X Lu, J.Q Wang, D.L. Qiu, Test of water seepage capacity of different structures and its implications for sponge city construction[J](School of Water Conservancy and Civil Engineering, South China Agricultural University, Guangzhou 510642, China)

3. Yan Pan, Che Wu, Zhao Yang, Li Junqi, Wang Sisi. Landscape Architecture,(02).(2013)

4. Janet Yip Cheng Leong, Meng Nan Chong, Phaik Eong Poh et al.. J Clean Prod,176. (2018)

5. R-H. Kim, S. Lee, Y-M. Kim et al..Environmental Technology,26(4). (2005)

6. C. Maduka Ignatius. Res J Environ Earth Sci,2(1). (2010)

7. Henrieta Pavolová, Tomáš Bakalár, Dušan Kudelas et al. J Clean Prod, 209. (2019)

8. K. E. Altieri, B. J. Turpin, S. P. Seitzinger. Oligomers, organosulfates, and nitrooxy organosulfates in rainwater identified by ultra-high resolution electrospray ionization FT-ICR mass spectrometry[J]. Atmos. Chem. Phys., 9(7). (2009)

9. A. Alcolea, C. Fernández-López, M. Vázquez et al..Atmos Envron,107. (2015)

10. B.I. Djon Li Ndjock, Antoine Elimbi, Martin Cyr. Rational utilization of volcanic ashes based on factors affecting their alkaline activation[J]. J Non-Cryst Solids,463. (2017) 
11. K. Zhu, Linus Zhang, William Hart et al. J Arid Environ, 57(4).(2004)

12. R.X. Hao, Y.W. Zhou, P. Liang et al..J Environ Sci Heal A, 41(7).(2006)

13. S. Ward, F.A. Memon, D. Butler. Water Res,46(16). (2012)

14. V. C. Chiang, M. H. Kao, J. C. Liu. Water Sci \& Technol, 67(3).(2012)

15. Jayati Chatterjee, Sunil Kumar Singh. Atmos Envron, 63.(2012)

16. MASATO IWASHITA, AYAMI SAITO, MIKA ARAI et al.. Geochem J,45(3). (2011)

17. Ramon Farreny, Tito Morales-Pinzón, Albert Guisasola et al..Water Res, 45(10).(2011) 